\title{
Development of Usability Framework for Projection Mapping to increase Food Dining Experience
}

\author{
Zeerak Qamar Shah ${ }^{1}$, Raja Rina Raja Ikram ${ }^{2}$ Syarulnaziah Anawar ${ }^{3}$, Noor Fazilla Abd Yusof ${ }^{4}$, \\ Ariff Idris ${ }^{5}$ \\ ${ }^{1}$ Center for Advanced Computing Technology (C-ACT), Fakulti Teknologi Maklumat dan Komunikasi, \\ Universiti Teknikal Malaysia (UTeM), 76100 Durian Tunggal, Melaka, Malaysia, zeerak320@gmail.com \\ ${ }^{2}$ Center for Advanced Computing Technology (C-ACT), Fakulti Teknologi Maklumat dan Komunikasi, \\ Universiti Teknikal Malaysia (UTeM), 76100 Durian Tunggal, Melaka, Malaysia, raja.rina@utem.edu.my \\ ${ }^{3}$ Center for Advanced Computing Technology (C-ACT), Fakulti Teknologi Maklumat dan Komunikasi, \\ Universiti Teknikal Malaysia (UTeM), 76100 Durian Tunggal, Melaka, Malaysia, syarulnaziah @utem.edu.my \\ ${ }^{4}$ Center for Advanced Computing Technology (C-ACT), Fakulti Teknologi Maklumat dan Komunikasi, \\ Universiti Teknikal Malaysia (UTeM), 76100 Durian Tunggal, Melaka, Malaysia, elle@utem.edu.my \\ ${ }^{5}$ Center for Advanced Computing Technology (C-ACT), Fakulti Teknologi Maklumat dan Komunikasi, \\ Universiti Teknikal Malaysia (UTeM), 76100 Durian Tunggal, Melaka, Malaysia, miariff@utem.edu.my
}

\begin{abstract}
This paper presents a software usability framework for an augmented reality technology, projection mapping, to improve food dining experience. This study will particularly focus on the dining atmosphere dimension. A literature review was conducted to identify the themes for usability in the software quality framework based on the definition of usability by the International Organization for Standardization (ISO) standard - effective, efficient and satisfaction. A total of five main themes were identified. A case study was conducted where subject matter experts from the projection mapping field to identify additional themes. A total of eight themes were identified from this study. These themes were then integrated with the literature view and mapped to the usability definition by International Organization for Standardization (ISO). Results show that the themes identified in this pilot case study match the themes identified in the literature review. The final framework proposes five main themes for projection mapping usability accuracy, integration, impact, emotional influence and interactive.
\end{abstract}

Key words : Projection mapping, dining experience, Mapping

\section{INTRODUCTION}

Projection mapping, also known as video mapping and spatial augmented reality, uses a daily video projector instead of projecting an image onto a flat screen, but projecting the image at any on the surface of the regular shape of the 3D object and through the control of the software, the interaction between the 3D object and the image light is called real-time projection mapping [1].

Projection mapping can be used for advertising, live concerts, drama, games, calculations, decoration, and many other purposes. The widespread use of projection mapping technology in recent years has turned buildings and other planes into dynamic art. The development of dynamic graphics, video, 3D animation, and other new technologies has enabled event organizers, and planners now have more and more innovative ways to convey brand information, provide a unique stage background, decorate walls and ceilings, and evoke emotional resonance[2].

Projection mapping is a new way of communicating and promoting events, user experience, and products. It is especially useful from the point of view of marketing for those who want to send a message in a striking and visually appealing way with guaranteed public exposure. These days, projection mapping is used to analyse system usability including user experience[3] [4]. The experience interacting with a service, company, or brand is abstract and invisible. Thus, providing a clear framework to guide development of projection mapping content creators to assist in modelling their actions, thoughts, and feelings provides new insight into improvements and opportunities [5][6]. This paper shall present projection mapping usability guideline for media creators and food industry that can be adhered to in order to increase the food dining experience.

\section{USABILITY DEFINITION}

Usability is defined as the "extent to which a product can be used by specified users to achieve specified goals with effectiveness, efficiency and satisfaction in a specified context of use" [7]. Measuring and tracking usability is an ongoing challenge for organizations that are concerned with 
improving user experience. Standards from the International Organization for Standardization (ISO) are produced by international groups of experts after a rigorous review process, and represent a consensus on the current state-of-the art. Because of the number of international experts involved in their development they provide a more balanced perspective than is typically found in textbooks or individual publications [8].

The version of ISO 9241-11 retains and elaborates on the concepts in the 1988 version of the standard, with the original definition of usability extended to apply to systems and services: "the extent to which a system, product or service can be used by specified users to achieve specified goals with effectiveness, efficiency and satisfaction in a specified context of use". The content has been extended to include current approaches to usability and user experience [8] [9].

In particular, ISO defines effectiveness as the "accuracy and completeness with which users achieve specified goals," efficiency as the "resources used in relation to the results achieved" and satisfaction as the "person's perceptions and responses that result from the use of a system, product or service". Table 1 presents the definition of usability based on ISO 9241. This article presents a usability framework for projection mapping to improve food dining experience based on the three criteria specified by ISO 9241-11.

Table 1: Definition of Usability from ISO 9241-11 [8]

\begin{tabular}{|l|l|}
\hline $\begin{array}{l}\text { Usability } \\
\text { Element }\end{array}$ & Description \\
\hline Effectiveness & $\begin{array}{l}\text { accuracy and completeness with which users } \\
\text { achieve specified goals }\end{array}$ \\
\hline Efficiency & $\begin{array}{l}\text { resources used in relation to the results } \\
\text { achieved }\end{array}$ \\
\hline Satisfaction & $\begin{array}{l}\text { person's perceptions and responses that } \\
\text { result from the use of a system, product or } \\
\text { service }\end{array}$ \\
\hline
\end{tabular}

\section{FOOD DINING EXPERIENCE}

The food dining experience can be divided into three main criteria's - food quality [7], [11]-[13], service quality [10], [14]-[16] and restaurant atmosphere [10], [17]-[19]. The food dining experience is defined as subjective reactions of people based on direct and indirect interaction with service providers. This makes it difficult to interpret the dining experience from an operational or consumer perspective. The most important parameters of the restaurant is determined namely the quality of food and drink, as well as the atmosphere of the restaurant and the service [14], which influenced the choice of dishes and determined customer satisfaction and future behaviour in the restaurant. Regardless of the atmosphere of the restaurant, consumers will not eat just to meet their basic needs. Experience is not just-food. Consumers are going to celebrate, relax or rejuvenate special events. In addition, researchers have different conditions for this experience. Table 2 shows the dimension of food dining experience and reference study.
Table 2: Dimensions of Food Dining Experience

\begin{tabular}{|l|l|}
\hline $\begin{array}{l}\text { Food Dining Experience } \\
\text { Dimension }\end{array}$ & Reference Study \\
\hline Service Quality & {$[7],[11]-[13]$} \\
\hline Food quality & {$[10],[14]-[16]$} \\
\hline Restaurant Atmosphere & {$[10],[17]-[19]$} \\
\hline
\end{tabular}

Hussein [20] confirm that the consumer sees the dining experience as a combination of ideal functions, also known as the dimension, attributes, or variables of the dining experience. Different definitions of these parameters / attributes or variables for lunch experience have been developed. According to [21], these dimensions of the dining experience are variable for the products / products that constitute the specific dining experience. Each set of sizes of eating experiences has different importance. These eateries are the cornerstones that consumers use to evaluate quality and make purchasing decisions. For example, the overall quality of the restaurant environment is assessed based on the prevalence of certain parameters of the dining experience and the consumer assessment for each dimension. Measuring the dining experience [17] can also be seen as a key factor in improving quality and customer satisfaction.

Every restaurant must find ways to retain and attract new customers, and restaurants must remain competitive and profitable. Now, for some reason, it is not surprising that many consumers are smarter than looking for unique menus, which not only offer unique menus at reasonable prices but also a pleasant atmosphere and a warm atmosphere. This includes integrating projection mapping into their restaurant atmosphere. As a result, the new informal restaurant creates a new concept of greater diversity and international integration, so the main competitive advantage depends on the ability of the restaurant to offer customers a more complete and memorable dining experience, which is more important than ever [21]. Thus, this paper shall focus on a usability framework for projection mapping to improve restaurant atmosphere, which is a dimension of the food dining experience.

\section{PROBLEM AND ITS CONTEXT}

While many inexperienced food restaurants work frantically, there are not enough human resources to accurately grasp and handle customer's food dining experiences. As a result, various food restaurants must work to deal every customer from the initial stage, which tends to decrease their revenues and results in loss of customers due to not meeting their satisfaction level. Even an experienced restaurant loses many customers due to the lack of proper analyses of customer experiences and their satisfaction level, which affects their overall sales. In order to get proper feedback and a chance to overcome the weak points in the food dining experience of customer's projection mapping techniques have been introduced these days within the food industry. This paper proposes a usability framework for 
projection mapping to enhance food dining experience in order to provide a guideline for projection mapping developers to develop improved projection mapping products to tailor the food dining industry.

\section{METHODOLOGY}

A literature review was done to identify a list of usability elements of a projection mapping product. In addition, an initial study using an open ended questionnaire was distributed to subject matter experts from the projection mapping and food dining industry. The questions asked were their definition of usability for projection mapping in the food industry. based on the three criteria defined in ISO 9241: effectiveness, efficiency and satisfaction

Q1: How would you define an effective projection mapping prototype?

Q2: How would you define an efficient projection mapping prototype?

Q3: What criteria should a projection mapping prototype have to achieve user satisfaction?

Q4:How would you define a projection mapping prototype that has is able to achieve the satisfaction of its users?

Q4: What reaction or response would you expect from a user that is satisfied with the projection mapping prototype?

In addition, they were also questioned regarding the required or desired criteria that they propose to have in a projection mapping product.

\section{LITERATURE REVIEW RESULTS AND DISCUSSION}

The outcome of usability criteria for projection mapping are shown in Table 3.

Table 3: Usability Elements for Projection Mapping

\begin{tabular}{|l|l|}
\hline $\begin{array}{l}\text { Usability } \\
\text { Criteria }\end{array}$ & Description \\
\hline Accuracy & $\begin{array}{l}\text { Timing of demonstration and utilization of } \\
\text { projection area [19][2] }\end{array}$ \\
\hline $\begin{array}{l}\text { Emotional } \\
\text { Influence }\end{array}$ & $\begin{array}{l}\text { Influence preferences , creates memories to } \\
\text { customer [20][21] }\end{array}$ \\
\hline Integration & $\begin{array}{l}\text { Integration of content, display processes and } \\
\text { team synchronization [2][22] }\end{array}$ \\
\hline Impact & Presentation of visual effects [23][24] \\
\hline Interactive & Engagement with users [22][25][26] \\
\hline
\end{tabular}

\subsection{Accuracy}

It is important for target surface can be displayed in pixels on the video, so improving the quality of the content is, in part, dependent on a very accurate comparison with the target surface and the technique to reach this level of accuracy [22] . If there is a problem, it can attract the attention of the public and reduce the impact of the message. When planning the project workflow, enough time for a demonstration is important to fully utilize the projected area per square inch [2]

\subsection{Emotional Influence}

Another main factor identified is the emotional prevalence that one create for their audience, because it determines their preferences, creates memories and ultimately forms one's behaviour [23]. Technical elements should be clearer to cause stronger emotional reactions in a projection mapping [23], [24].

\subsection{Integration}

For a projection display project to be fully successful, messages, content development, display processes, and event generation must be fully integrated.[25] Everyone, from the customer to the production team, must have the same information, communicate the same and have the same goals. It is important that every team stays in sync. For example, if content creators go too far, members of other teams may miss opportunities to find problems that confront the entire project [2].

\subsection{Impact}

A delivery system can make a big difference if one wants to improve the content. Customers who want the projection to be extremely clear can use other projectors. Some elements that can be processed by four projectors add visual effects as more projectors are added to the combination[26], [27].

\subsection{Interactive}

Attracting viewers to the audience is not just a passive audience. Viewers want to be participants and makers of their own experience. Speakers and suppliers who, experienced marketers make their activities as interactive as possible as they meet these basic needs are the ones who seek renewed engagement [25], [28] . Therefore enable viewers to communicate with the brand and not just communicate with them. Interoperability also creates license-based communication instead of interrupt-based communication [29].

\section{SUBJECT MATTER EXPERT CASE STUDY}

A total of five projection mapping subject matter experts were questioned in this initial study. The subject matter experts had between 2 to 10 experience in projection mapping or food industry that apply relevant projection mapping techniques. When asked regarding definition of effective projection mapping prototype, the subject matter experts agreed with the themes effective demonstration timing and effective utilization of projection area as shown in Figure 1. Demonstration timing is important to ensure it is optimal to improved dining experience. However, a subject matter expert had suggested mesmerizing and usage of lenticular 
projection mapping method which is part of the theme of presentation of visual effects.

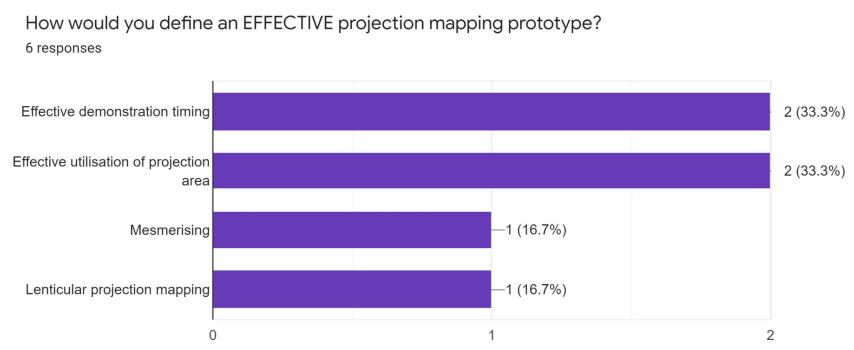

Figure 1: Effective Projection Mapping Prototype Response by Subject Matter Experts

When asked regarding their opinions on an efficient projection mapping prototype, the subject matter experts responded according to Figure 2.

Subject matter experts agreed on three themes for an efficient projection mapping prototype. The first theme is efficient integration of projection mapping content. The second theme mentioned by the subject matter expert is efficient integration of display processes. Projection mapping content development should be integrated from idea creation to display processes and final event production. The third theme agreed by subject matter experts are efficient team synchronization. In order to ensure efficient integration, critical team synchronization is important for a smooth projection presentation.

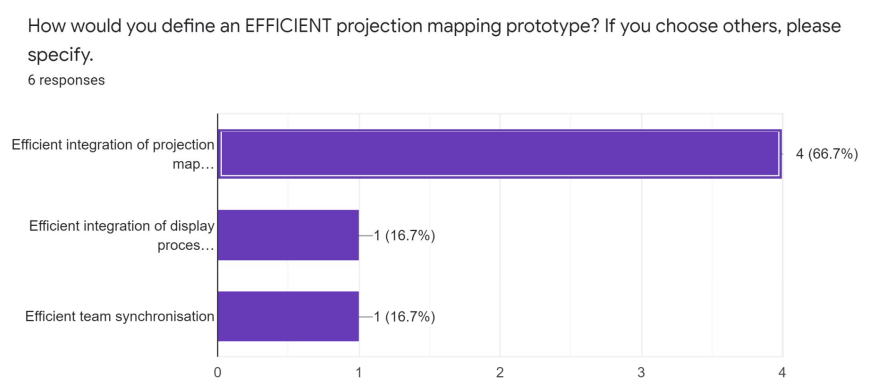

Figure 2: Efficient Projection Mapping Prototype Response by Subject Matter Experts

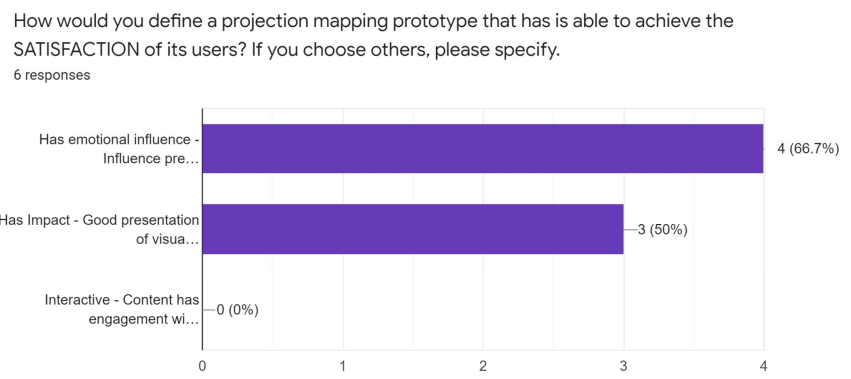

Figure 3: Satisfaction Projection Mapping Criteria Response by Subject Matter Experts
Referring to the third usability criteria - satisfaction, the subject matter experts response supported a projection mapping prototype that stirred emotional influence that is able to create memories to customers. This is also supported by responses that mentioned the projection mapping prototype should have a "wow" effect. Participants response towards a prototype with high satisfaction level are "Awesome!" and "Play that again!". It is also worth to note that the subject matter experts did not agree with a prototype that is interactive. An interactive prototype is a content that has engagement with the user, or respond differently based on the user's reaction towards the projection. The participants response can be grouped into the theme "Impact" as specified in the literature review results.

Table 4: Summary of Themes from Initial Case Study by Subject Matter Experts

\begin{tabular}{|l|l|}
\hline & Summary of Themes \\
\hline 1 & Effective demonstration timing \\
\hline 2 & Effective utilization of projection area \\
\hline 3 & Presentation of visual effects \\
\hline 4 & Efficient integration of projection mapping contents \\
\hline 5 & Efficient integration of display processes \\
\hline 6 & Efficient team synchronization \\
\hline 7 & Emotional influence \\
\hline 8 & Good presentation of visual effects. \\
\hline
\end{tabular}

The summary of themes collected from subject matter experts can be summarized in Table 4. The themes identified are effective demonstration timing, effective utilization of projection area, presentation of visual effects, efficient integration of projection mapping contents, efficient integration of display processes, efficient team synchronization, emotional influence and good presentation of visual effects.

It is worth to note that the themes identified in this case study also matches the themes as per the literature review. The next step is to map all the themes to the usability definition as per defined by ISO - efficient, effective and satisfaction.

\section{MAPPING WITH USABILITY DEFINITION}

The themes identified from the literature review and case study were then compiled to be mapped to the usability definition. The mapping results are summarized in Table 5.

Table 4: Projection Mapping Usability Themes

\begin{tabular}{|l|l|l|}
\hline $\begin{array}{l}\text { Usability } \\
\text { Definition }\end{array}$ & $\begin{array}{l}\text { Major } \\
\text { Theme }\end{array}$ & Sub Theme \\
\hline Effectiveness & Accuracy & Effective demonstration timing \\
\hline Efficient & $\begin{array}{l}\text { Integratio } \\
\mathrm{n}\end{array}$ & $\begin{array}{l}\text { Effictivent intiogation of } \\
\text { projection area }\end{array}$ \\
\hline
\end{tabular}




\begin{tabular}{|l|l|l|}
\hline & & $\begin{array}{l}\text { Efficient integration of display } \\
\text { processes }\end{array}$ \\
\hline & & Efficient team synchronization \\
\hline Satisfaction & Impact & Presentation of visual effects \\
\hline & $\begin{array}{l}\text { Emotional } \\
\text { Influence }\end{array}$ & $\begin{array}{l}\text { Influence preferences, creates } \\
\text { memories to customer }\end{array}$ \\
\hline & Interactive & Engagement with users \\
\hline
\end{tabular}

There are three criteria of usability - effectiveness, efficient and satisfaction [30]. The major themes that group the subthemes are identified as accuracy, integration, impact, emotional influence and interactive. The subthemes identified are effective demonstration timing, effective utilization of projection area, efficient integration of projection mapping contents, efficient integration of display processes, efficient team synchronization, presentation of visual effects, influence preferences, creates memories to customer and engagement with users. It is also noted that the Interactive theme was not removed from the theme even though it was not identified as a theme in the case study as the case study is a pilot study and the author assume that the themes should not be isolated at the early stage until the framework is stable and finalized.

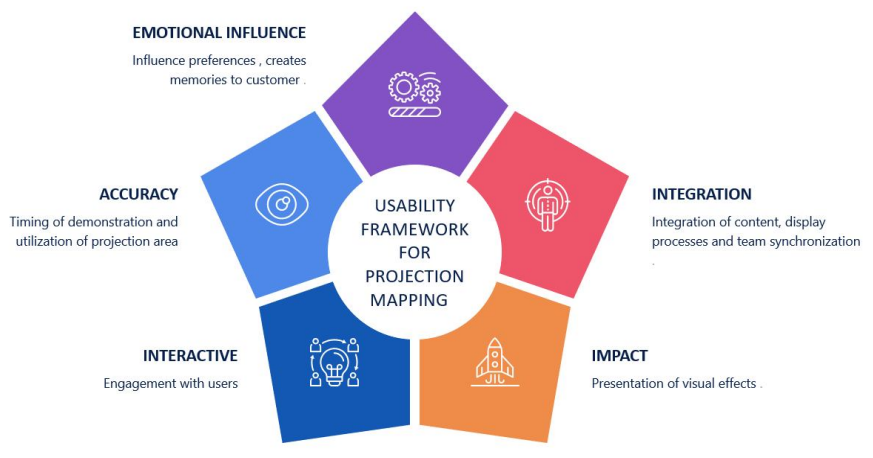

Figure 4: Projection Mapping Usability Framework

Thus, based on the summary of themes and mapping in Table 5, the proposed Projection Mapping Usability Framework to increase dining experience can be modelled in Figure 4. The food dining experience that is focused to be improved using this framework is the atmosphere dimension. This is because food quality and service quality is not highly influenced by projection mapping although there is evidence projection mapping can improve the food visualization. However, the purpose of this study shall only focus on the atmosphere of the food dining experience.

\section{CONCLUSION}

This paper has presented a projection mapping usability framework to improve food dining atmosphere based on the usability guideline by International Organization for Standardization (ISO) 9241. This study is still a pilot study and more subject matter experts can be used to improve the results and provide more reliability for the study.

\section{ACKNOWLEDGMENT}

This paper has been supported by Center for Advanced Computing Technology (C-ACT), Fakulti Teknologi Maklumat dan Komunikasi, Universiti Teknikal Malaysia (UTeM).

\section{REFERENCES}

1. M. Bruijnes, G. Huisman, and D. Heylen, "Tasty Tech: Human-food interaction and multimodal interfaces," Nov. 2016, doi: 10.1145/3007577.3007581.

2. D. Lindlbauer, J. E. Grønbæk, M. Birk, K. Halskov, M. Alexa, and J. Müller, "Combining shape-changing interfaces and spatial augmented reality enables extended object appearance," in Conference on Human Factors in Computing Systems - Proceedings, May 2016, pp. 791-802, doi: 10.1145/2858036.2858457.

3. P. S. Jerome, M. S. Ariel, and P. M. Ruji, "Towards Usability Evaluation of Jumbled PassSteps," International Journal of Advanced Trends in Computer Science and Engineering, vol. 8, no. 4, pp. 1032-1037, 2019, doi: https://doi.org/10.30534/ijatcse/2019/08842019.

4. T. Hoang, M. Reinoso, Z. Joukhadar, F. Vetere, and D. Kelly, "Augmented studio: Projection mapping on moving body for physiotherapy education," in Conference on Human Factors in Computing Systems - Proceedings, May 2017, vol. 2017-May, pp. 1419-1430, doi: 10.1145/3025453.3025860.

5. R. Alnanih, N. Bahatheg, M. Alamri, and R. Algizani, "Mobile-d approach-based persona for designing user interface," International Journal of Advanced Trends in Computer Science and Engineering, vol. 8, no. 5, pp. 2597-2607, 2019, doi: 10.30534/IJATCSE/2019/111852019.

6. I. B. Mehmet and K. Dilek, "Re-Assessing the Usability Metric for User Experience (UMUX) Scale," Journal of Usability Studies, vol. 11, no. 3, pp. 89-109, 2016, Accessed: Jun. 10, 2020. [Online]. Available:

https://uxpajournal.org/wp-content/uploads/sites/8/p df/JUS_Berkman_May2016.pdf.

7. S. Lee, W. A. Khan, J. Hussain, B. Ali, and A. Satti, "A lean process for selecting appropriate UX evaluation methods and techniques in AR/VR. Team: ISO/IEC JTC 1/SC 24," 2018.

8. N. Bevan, J. Carter, J. Earthy, T. Geis, and S. Harker, "New ISO standards for usability, usability reports and usability measures," in Lecture Notes in Computer Science (including subseries Lecture Notes in Artificial Intelligence and Lecture Notes in Bioinformatics), 2016, vol. 9731, pp. 268-278, doi: 10.1007/978-3-319-39510-4_25. 
9. E. Nuraihan et al., "Enhancing Food Taste Experience with 3600 Immersive Virtual Reality ( IVR )," International Journal of Advanced Trends in Computer Science and Engineering, vol. 8, no. 1, pp. 394-400, 2019,

doi: https://doi.org/10.30534/ijatcse/2019/5781.62019.

10. M. Mannan, N. Chowdhury, P. Sarker, and R. Amir, "Modeling customer satisfaction and revisit intention in Bangladeshi dining restaurants," Journal of Modelling in Management, vol. 14, no. 4, pp. 922-947, Oct. 2019,

doi: 10.1108/JM2-12-2017-0135.

11. M. Nakayama and Y. Wan, "Is culture of origin associated with more expressions? An analysis of Yelp reviews on Japanese restaurants," Tourism Management, vol. 66, pp. 329-338, Jun. 2018, doi: 10.1016/j.tourman.2017.10.019.

12. M. Aliff, A. Majid, M. Izwan, and M. Zaki, "Service Quality, Food Quality, Image and Customer loyalty: An Empirical Study at a Hotel Restaurant," 2018, doi: 10.6007/IJARBSS/v8-i10/5310.

13. S. Richardson, M. Lefrid, S. Jahani, M. D. Munyon, and S. M. Rasoolimanesh, "Effect of dining experience on future intention in quick service restaurants," British Food Journal, vol. 121, no. 11, pp. 2620-2636, Oct. 2019,

doi: 10.1108/BFJ-09-2018-0617.

14. B. Almohaimmeed and B. M. A Almohaimmeed, "Restaurant Quality and Customer Satisfaction International Review of Management and Marketing Restaurant Quality and Customer Satisfaction," International Review of Management and Marketing, vol. 7, no. 3, pp. 42-49, 2017, Accessed: Jun. 16, 2020. [Online]. Available: http:www.econjournals.com.

15. K. Ryu and J. S. Lee, "Examination of Restaurant Quality, Relationship Benefits, and Customer Reciprocity From the Perspective of Relationship Marketing Investments," Journal of Hospitality and Tourism Research, vol. 41, no. 1, pp. 66-92, Jan. 2017, doi: 10.1177/1096348013515919.

16. H. Han and S. S. Hyun, "Impact of hotel-restaurant image and quality of physical-environment, service, and food on satisfaction and intention," International Journal of Hospitality Management, vol. 63, pp. 82-92, May 2017, doi: 10.1016/j.ijhm.2017.03.006.

17. P. Liu and E. C. Y. Tse, "Exploring factors on customers' restaurant choice: an analysis of restaurant attributes," British Food Journal, vol. 120, no. 10, pp. 2289-2303, Oct. 2018,

doi: 10.1108/BFJ-10-2017-0561.

18. A. Garg and M. Amelia, "Service Clues' Inluence on Customers' Dining Experience in Fine Dining Restaurants 91," Asia-Paciic Journal of Innovation in Hospitality and Tourism APJIHT, vol. 5, no. 1, pp.
91-109, 2016.

19. M. Shahzadi, S. A. Malik, M. Ahmad, and A. Shabbir, "Perceptions of fine dining restaurants in Pakistan: What influences customer satisfaction and behavioral intentions?," International Journal of Quality and Reliability Management, vol. 35, no. 3, pp. 635-655, 2018, doi: 10.1108/IJQRM-07-2016-0113.

20. A. S. Hussein, "Revisiting the importance of casual dining experience quality: an empirical study," International Journal of Quality and Service Sciences, vol. 10, no. 3, pp. 233-252, Sep. 2018, doi: 10.1108/IJQSS-04-2017-0041.

21. Y. Fujimoto, "Food appearance optimizer: Automatic projection mapping system for enhancing perceived deliciousness based on appearance," in 26th IEEE Conference on Virtual Reality and 3D User Interfaces, VR 2019 Proceedings, Mar. 2019, pp. 927-928, doi: 10.1109/VR.2019.8797732.

22. H. Asayama, D. Iwai, and K. Sato, "Fabricating Diminishable Visual Markers for Geometric Registration in Projection Mapping," IEEE Transactions on Visualization and Computer Graphics, vol. 24, no. 2, pp. 1091-1102, Feb. 2018, doi: 10.1109/TVCG.2017.2657634.

23. Y. He, J. H. Kim, and J. W. Park, "Analysis on Manifestation Mode of Ideological Implication in Projection Mapping: Take Work Ring as an Example," TECHART: Journal of Arts and Imaging Science, vol. 5, no. 2, pp. 1-4, May 2018, doi: 10.15323/techart.2018.05.5.2.1.

24. J. Lee, S. Jung, J. W. Kim, and F. Biocca, "Applying Spatial Augmented Reality to Anti-Smoking Message: Focusing on Spatial Presence, Negative Emotions, and Threat Appraisal," International Journal of Human-Computer Interaction, vol. 35, no. 9, pp. 751-760, May 2019, doi: 10.1080/10447318.2018.1489581.

25. A. D. Wilson and H. Benko, "Projected augmented reality with the RoomAlive Toolkit," in Proceedings of the 2016 ACM International Conference on Interactive Surfaces and Spaces: Nature Meets Interactive Surfaces, ISS 2016, Nov. 2016, pp. 517-520, doi: 10.1145/2992154.2996362.

26. G. Huisman, M. Bruijnes, and D. K. J. Heylen, "Moving feast: Effects of color, shape and animation on taste associations and taste perceptions," Nov. 2016, doi: 10.1145/3001773.3001776.

27. H. Y. Pai, "An imitation of 3D projection mapping using augmented reality and shader effects," Aug. 2016, doi: 10.1109/ICASI.2016.7539879.

28. P. Punpongsanon, D. Iwai, and K. Sato, "FleXeen: Visually Manipulating Perceived Fabric Bending Stiffness in Spatial Augmented Reality," IEEE Transactions on Visualization and Computer 
Graphics, vol. 26, no. 2, pp. 1433-1439, Feb. 2020, doi: 10.1109/TVCG.2018.2871044.

29. N. Kotani and S. Mizuno, "A proposal of interactive projection mapping by touching rays visualized by smoke," in Proceedings - 2019 NICOGRAPH International, NicoInt 2019, Jul. 2019, p. 121, doi: 10.1109/NICOInt.2019.00035.

30. C. S. Dietlein and O. L. Bock, "Development of a usability scale based on the three ISO 9241-11 categories 'effectiveness,' 'efficacy' and 'satisfaction': a technical note,' Accreditation and Quality Assurance, vol. 24, no. 3, pp. 181-189, Jun. 2019, doi: 10.1007/s00769-018-01368-2. 